\title{
Optimal Placement of Distributed Generations in Radial Distribution Systems Using Various PSO and DE Algorithms
}

\author{
H. Manafi ${ }^{1}$, N. Ghadimi ${ }^{2}$, M. Ojaroudi ${ }^{2}$, P. Farhadi ${ }^{3}$ \\ ${ }^{1}$ Department of Electrical and Computer Engineering, MeshkinShahr Branch, \\ Islamic Azad University, \\ MeshkinShahr, Iran \\ ${ }^{2}$ Young Researchers Club, Ardabil Branch, Islamic Azad University, \\ Ardabil, Iran \\ ${ }^{3}$ Young Researchers Club, Parsabad Moghan Branch, Islamic Azad University, \\ Pasabad Moghan, Iran \\ noradin.ghadimi@gmail.com
}

\begin{abstract}
Distributed generations (DGs) have been continuously integrating into the distribution systems. Size and site of distributed generations have significant impacts on the system real power losses reduction and voltage profile improvement in the radial distribution systems. In this paper, recent and more dynamic PSO as well as improved DE algorithms are used for optimum placement of distributed generations in radial distribution systems. The objective of this paper is to minimize distribution system real power losses by the least possible injected power from distributed generations. To assess different PSO and DE algorithms capabilities, simulations carried out on two IEEE 33-bus and 69-bus standard radial distribution systems.
\end{abstract}

Index Terms-Differential evolutionary algorithm, distributed generation, particle swarm optimization algorithm, radial distribution systems, real power losses.

\section{INTRODUCTION}

Distributed Generations (DGs) are mentioned usually to the production of electricity using small generators located in power distribution systems or the power load centers. The reasons for implementation of DGs have been motivated due to the different factors such as recent advances in small and efficient generation technologies, increasing interests in the environmental issues, postponing investment on new power transmission and distribution networks, and the need for more reliable and flexible electric power systems [1]-[3].

Many potential benefits of DGs depend on the size and location of DGs. In this regard, there have been different methodologies which have been proposed for optimal placement of DGs. For solving the DG placement optimization problem, a mixed integer linear program was formulated. The objective function was to optimal determination of the DG unit mix on a network section [4]. Tabu Search (TS)-based method was proposed to determine

Manuscript received June 19, 2012; accepted September 27, 2013.

This research was funded by I.A.U. the optimum solution for the DG placement problem, however, the TS has some drawbacks such as being timeconsuming algorithm in addition that it is trapped in local minima [5]. An analytical expression was introduced for finding optimal size and power factor of four types of DG units. DG units are sized to reach the highest real power loss reduction in distribution networks [6]. In [7], a novel optimization approach that employs an Artificial Bee Colony (ABC) algorithm to find the optimum DG size, power factor, and location in order to minimize the total system real power loss. A multi-objective optimization algorithm was suggested in [8], its objectives consist of minimization of costs, emission and power losses of distribution system and voltage profile improvement. This multi-objective optimization was solved by the modified Honey Bee Mating Optimization (HBMO) algorithm. Genetic Algorithm (GA)based technique together with Optimal Power Flow (OPF) calculations was utilized to determine the optimum size and location of DG units installed on the system for minimization of the cost of active and reactive power generation. Like TS, the GA is a time-consuming method, although it can reach global or near-global solutions [9].

Particle Swarm Optimization (PSO) algorithm is motivated by social behavior of animals such as bird flocking and fish schooling which was introduced first by Kennedy and Eberhart [10]. In a PSO algorithm, particles fly around in a multi-dimensional search space, and each particle adjusts its position according to its own experience, and the experience of other neighboring particles as well. PSO algorithm is very easy for implementation and has few parameters for adjustment. PSO and its various branches have been utilized in many power system optimization problems [11]. Differential Evolution (DE) is a simple while powerful Evolutionary Algorithm (EA) for global optimization which was introduced by Price and Storn. The $\mathrm{DE}$ algorithm has gradually become more popular and has been used in many practical uses, mainly due to its good 
convergence properties and is principally easy to understand $[12,13]$. In this paper, several advanced and evolved PSO and DE techniques are utilized for optimal DG allocation.

Rest of the paper is organized as follows: Section II presents problem formulation and objective function. PSO and DE Techniques for finding optimal sizes and locations of various DG sizes are included and referred in Section III. Case studies for optimum DG placement on two IEEE 33bus and 69-bus radial distribution systems are addressed in Section IV. At the end, conclusions are sum up in Section V.

\section{PROBLEM FORMULATION}

To solve DG placement problem, first a power flow method should be used. The goal of a power flow calculation is obtaining complete voltage angles and magnitudes information for each bus in a power system. In this paper, power flow calculation which is forward-backward (fw-bw) method is also necessary to obtain the variation of power and voltage when some DGs are installed into the system.

\section{A. Objective Function}

Mathematically, the objective function is formulated to minimize the total real power losses as (1)

$$
\text { O.F. }=\sum_{i=1}^{n} \sum_{j=1}^{n} A_{i j}\left(P_{i} P_{j}+Q_{i} Q_{j}\right)+B_{i j}\left(Q_{i} P_{j}-P_{i} Q_{j}\right),
$$

where $\mathrm{A}_{\mathrm{ij}}=\frac{\mathrm{R}_{\mathrm{ij}} \cos \left(\delta_{\mathrm{i}}-\delta_{\mathrm{j}}\right)}{\mathrm{V}_{\mathrm{i}} \mathrm{V}_{\mathrm{j}}}, \mathrm{B}_{\mathrm{ij}}=\frac{\mathrm{R}_{\mathrm{ij}} \sin \left(\delta_{\mathrm{i}}-\delta_{\mathrm{j}}\right)}{\mathrm{V}_{\mathrm{i}} \mathrm{V}_{\mathrm{j}}}, P_{i}$ and $Q_{i}$ are real and reactive power injection in bus $i . R_{i j}$ is the resistance between $i$ th and $j$ th bus. $V_{i}$ and $\delta_{i}$ are the voltage magnitude and angle of $i$ th bus. $V_{j}$ and $\delta_{j}$ are the voltage magnitude and angle of $j$ th bus.

\section{B. Problem Constraints}

In this paper, optimization problem is solved subject to several problem constraints which are given further.

Load balance: For each bus, to meet demand and supply the following equations should be satisfied

$$
P_{\text {Slack }}+\sum_{i=1}^{N} P_{D G i}=\sum_{i=1}^{N} P_{D i}+P_{L}
$$

Voltage limits: For each bus, there should be an upper and lower voltage bounds

$$
\left|V_{i}\right|^{\min } \leq\left|V_{i}\right| \leq\left|V_{i}\right|^{\max },
$$

where $\left|V_{i}\right|^{\min }=0.95$ p.u. and $\left|V_{i}\right|^{\max }=1.05$ p.u.

Active (real) and reactive power limit of $D G$ : To size DGs, there should be a range of available DG size:

$$
\begin{aligned}
Q_{D G i}^{\min } & \leq Q_{D G i} \leq Q_{D G i}^{\max }, \\
P_{D G i}^{\min } & \leq P_{D G i} \leq P_{D G i}^{\max } .
\end{aligned}
$$

Real power loss limits: It is obvious that Total Real Power Loss should be decreased after DG installation

$$
\sum \operatorname{Loss}_{k}(\text { withDG }) \leq \sum \operatorname{Loss}_{k}(\text { withoutDG }) .
$$

\section{OPtIMIZATION ALGORITHMS: PSO AND DE}

The reason for selecting PSO as an optimization algorithm is that in PSO there is neither competition between particles nor self-adaptation of the strategic parameters. The progression towards the optimum solution is governed by the movement equation. PSO has the fast convergence ability which is a great attractive property for a large iterative and time consuming problem [14]. While, the reason why we chose DE is for its good convergence properties. It has only a few control parameters kept fixed throughout the entire evolutionary process [15].

\section{A. Standard PSO}

In PSO, the optimization process begins with a randomly created population constituted by the so called particles. Each particle contains a position vector, a velocity vector and a memory vector of its previous best position. Each member of the population is moved in the search space according to three vectors called inertia (first term), memory (second term) and cooperation (third term) as (7)-(9):

$$
\begin{gathered}
\mathrm{v}_{\mathrm{i}}^{\mathrm{k}+1}=\omega \mathrm{v}_{\mathrm{i}}^{\mathrm{k}}+\mathrm{c}_{1} \mathrm{r}_{1}\left(\mathrm{X}_{\text {Pbest }_{\mathrm{i}}^{\mathrm{k}}}-\mathrm{X}_{\mathrm{i}}^{\mathrm{k}}\right)++\mathrm{c}_{2} \mathrm{r}_{2}\left(\mathrm{X}_{\text {Gbest }^{\mathrm{k}}}-\mathrm{X}_{\mathrm{i}}^{\mathrm{k}}\right), \\
\mathrm{x}_{\mathrm{i}}^{\mathrm{k}+1}=\mathrm{x}_{\mathrm{i}}^{\mathrm{k}}+\mathrm{v}_{\mathrm{i}}^{\mathrm{k}+1}
\end{gathered}
$$

where, $\omega \geq 0$ defined as inertia weight factor.

$$
\omega=\omega_{\max }-\frac{\omega_{\max }-\omega_{\min }}{i t e r_{\max }} \times \text { iter } .
$$

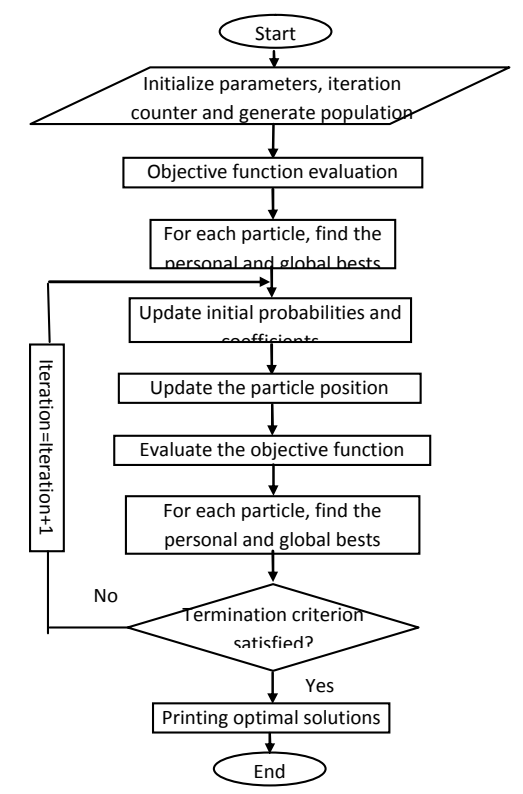

Fig. 1. Flowchart of PSO algorithms in problem solving

\section{B. Various PSO Branches}

So far various PSO techniques have been developed and implemented on various parts of engineering problems. Five improved PSOs are utilized in this paper for optimal placement of DGs [11]. The PSO techniques used in this paper are: Adaptive Dissipative PSO (ADPSO), Escape Velocity PSO (EVPSO), PSO with Passive Congregation 
(PSOPC), PSO with Area Extension (AEPSO) and Dynamic Adaptation of PSO (DAPSO) [16]-[20]. Figure 1 shows the computational flow chart of the PSO algorithms.

\section{Standard DE}

In general, DE algorithm has five stages. Figure 2 shows structure of the algorithm [21].

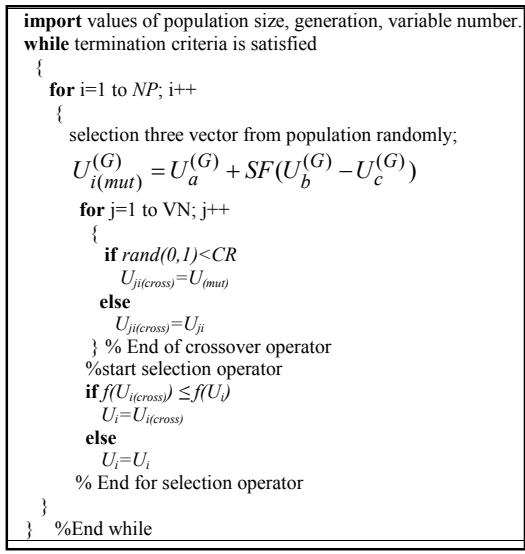

Fig. 2. Structure of simple DE algorithm.

Initialization: This algorithm is a population based algorithm, for this, initial population is produced as (10)

$$
\bar{Z}_{i, k}^{G}=\bar{Z}_{L}^{M I N}+\operatorname{rand} \times\left(\bar{Z}_{L}^{M A X}-\bar{Z}_{L}^{M I N}\right),
$$

where $i \in[1, P], L \in[1, V]$, to start optimization process. Dimensions of DE algorithm depend on the size of population $P$, and variable $V, Z_{L}{ }^{M I N}$ and $Z_{L}{ }^{M A X}$ are lower and upper boundaries, respectively, selected based on the type of problem. rand produces a value in [0,1], randomly.

Mutation: The initialized population is mutated using (11). Mutation operator helps algorithm to escape from local minima. For this, three vectors are randomly selected from initial population called $Z_{1}, Z_{2}$ and $Z_{3}$. Main criterion in production of mutated matrix is scaling factor, $F$, which is selected from $[0,2]$. The impact of $2^{\text {nd }}$ and $3^{\text {rd }}$ selected vectors, $Z_{2}$ and $Z_{3}$, in mutation process are controlled by $F$

$$
\bar{Z}_{m, i}^{G+1}=\bar{Z}_{1}^{G}+F\left(\bar{Z}_{2}^{G}-\bar{Z}_{3}^{G}\right)
$$

Crossover: By crossover operator, prior population (parent) is composed and then produces next population (children). Crossover operator is not applied on all population, and applying criteria is Crossover Rate, $C R$. This parameter has a real value in $[0,1]$. If crossover rate is more than a random value, vectors from mutation step are selected; otherwise, selection is performed from initial population

$$
\bar{Z}_{c, j i}^{G}=\left\{\begin{array}{lc}
\bar{Z}_{i}^{G+1}, & \text { if } \alpha_{j} \leq C R \text { or } j=\gamma, \\
\bar{Z}_{i}^{G}, & \text { otherwise }
\end{array}\right.
$$

where $i=1, \ldots, P, j=1, \ldots, V \quad \alpha_{j}$ and $\gamma$ are chosen randomly from $[1, \ldots, V]$.

Selection: In this stage, the algorithm uses selection operator to select optimal solution. In other words, selection operator decides between initial matrix, $Z_{i}$, and crossover matrix, $Z_{j i}$. If related solution of crossover vector, $f\left(Z_{c, i}{ }^{G}\right)$, is less or equal to solution corresponding to initial population, $f\left(Z_{i}^{G}\right)$, crossover vector is selected which is shows in (13)

$$
\bar{Z}_{i}^{G+1}=\left\{\begin{array}{lc}
\bar{Z}_{c, i}^{G}, & \text { if } f\left(\bar{Z}_{c, i}^{G}\right) \leq f\left(\bar{Z}_{i}^{G}\right), \\
\bar{Z}_{i}^{G}, & \text { otherwise }
\end{array}\right.
$$

where $i=1, \ldots, P$.

Termination Criteria: To terminate algorithm, there are two techniques; reaching optimal solution and finishing iteration number. In optimization problem, second criterion is used.

\section{D. Various DE Branches}

So far various DE techniques have been developed and improved. Three improved DEs are utilized in this paper for optimal placement of distributed generations [15], [22]. The DE techniques used in this paper are Self-Adaptive DE, Opposition-based DE, BSNN DE.

\section{CASE STUDY}

PSO and DE Techniques have been implemented in the MATLAB software for optimal sitting and sizing of DGs and tested on two standard IEEE 33-bus and 69-bus radial distribution systems.

\section{A. PSO Techniques, IEEE 33-bus Radial Distribution System}

The first system is a radial distribution system with the total load of $3720 \mathrm{~kW}, 2300 \mathrm{kVar}, 33$ bus and 32 branches, the real power losses in the system is $210.98 \mathrm{~kW}$ while the reactive power losses is at $143 \mathrm{kVar}$. The optimum results for each PSO technique are obtained with population size of 30 , after 30 runs and for power factor of 0.85 lagging (Table I-Table III).

TABLE I. SINGLE DG PLACEMENT RESULTS IN IEEE 33-BUS SYSTEM.

\begin{tabular}{|c|c|c|c|c|c|c|}
\hline \multirow{2}{*}{ Technique } & \multicolumn{2}{|c|}{$\begin{array}{c}\text { DG } \\
\text { Installation }\end{array}$} & \multicolumn{2}{c|}{ Power Loss } & \multicolumn{2}{c|}{ Bus Voltage } \\
\cline { 2 - 7 } & $\begin{array}{c}\text { Total } \\
\text { Size } \\
(\boldsymbol{k W})\end{array}$ & $\begin{array}{c}\text { a } \\
\text { bus }\end{array}$ & $\begin{array}{c}\text { Value } \\
(\boldsymbol{k W})\end{array}$ & $\begin{array}{c}\text { Decline } \\
(\%)\end{array}$ & $\begin{array}{c}\text { Min. } \\
(\boldsymbol{p} . \boldsymbol{u} .)\end{array}$ & $\begin{array}{c}\text { Mean } \\
(\boldsymbol{p} . \boldsymbol{u} .)\end{array}$ \\
\hline $\begin{array}{c}\text { Without } \\
\text { DG }\end{array}$ & - & - & 210.98 & - & 0.9038 & 0.9453 \\
\hline EVPSO & 763 & 11 & 140.19 & 33.55 & 0.9284 & 0.9604 \\
\hline PSOPC & 1000 & 15 & 136.75 & 35.18 & 0.9318 & 0.9679 \\
\hline AEPSO & 1200 & 14 & 131.43 & 37.70 & 0.9347 & 0.9715 \\
\hline ADPSO & 1210 & 13 & 129.53 & 38.60 & 0.9348 & 0.9712 \\
\hline DAPSO & 1212 & 8 & 127.17 & 39.70 & 0.9349 & 0.9635 \\
\hline
\end{tabular}

For single-DG placement, it was assumed that maximum DG size is less/equal to $1250 \mathrm{~kW}$ (Table I). As it can be seen from results in Table I, the minimum real power loss is achieved by DAPSO algorithm. The maximum real power loss reduction by DAPSO is at $39.70 \%$ in comparison to the case without DG installation. However, this solution does not lead to the best voltage profile because the main purpose is to minimize real power loss. AEPSO, ADPSO and DAPSO are marginally same for Min. and Mean voltage values. AEPSO has the best results for voltage profile, since it propose a DG near the lowest bus voltage (bus 18).

For double and triple-DG placement it was assumed that 
maximum DG size is less/equal to $2000 \mathrm{~kW}$ (Table II). The minimum real power loss is achieved again using DAPSO algorithm which the reduction is at $54.53 \%$ in comparison to the case without any DG installation. It is obvious that the more the DG size and DG number, the more is the benefits. Unlike single-DG placement, in this case DAPSO not only could reach the maximum real power loss reduction, but also suggests the best voltage profiles among all PSO techniques.

TABLE II. DOUBLE-DG PLACEMENT RESULTS IN IEEE 33-BUS SYSTEM.

\begin{tabular}{|c|c|c|c|c|c|c|}
\hline \multirow[b]{2}{*}{ Technique } & \multicolumn{2}{|c|}{ DG Installation } & \multicolumn{2}{|c|}{ Power Loss } & \multicolumn{2}{|c|}{ Bus Voltage } \\
\hline & $\begin{array}{l}\text { Size } \\
(k W)\end{array}$ & (a) bus & $\begin{array}{c}\text { Value } \\
(\mathbf{k} W)\end{array}$ & $\begin{array}{c}\text { Decline } \\
(\%)\end{array}$ & $\begin{array}{l}\text { Min. } \\
\text { (p.u.) }\end{array}$ & $\begin{array}{l}\text { Mean } \\
(\text { p.u. })\end{array}$ \\
\hline $\begin{array}{l}\text { Without } \\
\text { DG }\end{array}$ & - & - & 210.98 & - & 0.9038 & 0.9453 \\
\hline \multirow{2}{*}{ PSOPC } & 916 & 8 & \multirow{2}{*}{111.45} & \multirow{2}{*}{47.17} & \multirow{2}{*}{0.9418} & \multirow{2}{*}{0.9738} \\
\hline & 767 & 12 & & & & \\
\hline \multirow{2}{*}{ EVPSO } & 540 & 14 & \multirow{2}{*}{108.05} & \multirow{2}{*}{48.78} & \multirow{2}{*}{0.9457} & \multirow{2}{*}{0.9661} \\
\hline & 569 & 31 & & & & \\
\hline \multirow{2}{*}{ AEPSO } & 600 & 14 & \multirow{2}{*}{106.38} & \multirow{2}{*}{49.57} & \multirow{2}{*}{0.9447} & \multirow{2}{*}{0.9671} \\
\hline & 600 & 29 & & & & \\
\hline \multirow{2}{*}{ ADPSO } & 550 & 15 & \multirow{2}{*}{106.24} & \multirow{2}{*}{49.64} & \multirow{2}{*}{0.9467} & \multirow{2}{*}{0.9667} \\
\hline & 621 & 30 & & & & \\
\hline \multirow{2}{*}{ DAPSO } & 1227 & 13 & \multirow{2}{*}{95.93} & \multirow{2}{*}{54.53} & \multirow{2}{*}{0.9651} & \multirow{2}{*}{$0.981 \mathrm{C}$} \\
\hline & 738 & 32 & & & & \\
\hline
\end{tabular}

Studying results in Table III reveals that DAPSO and ADPSO could gain better results compared to the other techniques in real power loss reduction, by reducing real power loss to $56.13 \%$ and $55.43 \%$, respectively. In addition, DAPSO could improve voltage profile better than the other techniques. It should be mentioned that the size and number of DGs are very important in power loss reduction, and in particular for voltage profile improvement. Thus, to show this fact, voltage profile is depicted in Fig. 3 only for DAPSO and ADPSO as the two best techniques for three cases.

TABLE III. TRIPLE-DG PLACEMENT RESULTS IN IEEE 33-BUS SYSTEM.

\begin{tabular}{|c|c|c|c|c|c|c|}
\hline \multirow{2}{*}{ Technique } & \multicolumn{2}{|c|}{$\begin{array}{c}\text { DG } \\
\text { Installation }\end{array}$} & \multicolumn{2}{|c|}{ Power Loss } & \multicolumn{2}{|c|}{ Bus Voltage } \\
\hline & $\begin{array}{l}\text { Size } \\
(\mathrm{kW})\end{array}$ & $\begin{array}{c}\text { a } \\
\text { bus }\end{array}$ & $\begin{array}{l}\text { Value } \\
(\mathrm{kW})\end{array}$ & $\begin{array}{c}\text { Decline } \\
\text { (\%) }\end{array}$ & $\begin{array}{l}\text { Min. } \\
\text { (p.u.) }\end{array}$ & $\begin{array}{c}\text { Mean } \\
\text { (p.u.) }\end{array}$ \\
\hline $\begin{array}{c}\text { Without } \\
\text { DG }\end{array}$ & - & - & 210.98 & - & 0.9038 & 0.9453 \\
\hline \multirow{3}{*}{ AEPSO } & 300 & 11 & \multirow{3}{*}{103.58} & \multirow{3}{*}{50.90} & \multirow{3}{*}{0.9499} & \multirow{3}{*}{0.9676} \\
\hline & 354 & 16 & & & & \\
\hline & 533 & 32 & & & & \\
\hline \multirow{3}{*}{ PSOPC } & 663 & 3 & \multirow{3}{*}{100.34} & \multirow{3}{*}{52.44} & \multirow{3}{*}{0.9418} & \multirow{3}{*}{0.9697} \\
\hline & 621 & 6 & & & & \\
\hline & 633 & 12 & & & & \\
\hline \multirow{3}{*}{ EVPSO } & 398 & 16 & \multirow{3}{*}{95.63} & \multirow{3}{*}{54.67} & \multirow{3}{*}{0.9611} & \multirow{3}{*}{0.9754} \\
\hline & 389 & 18 & & & & \\
\hline & 801 & 32 & & & & \\
\hline \multirow{3}{*}{ ADPSO } & 846 & 16 & \multirow{3}{*}{94.02} & \multirow{3}{*}{55.43} & \multirow{3}{*}{0.9528} & \multirow{3}{*}{0.9758} \\
\hline & 384 & 26 & & & & \\
\hline & 499 & 30 & & & & \\
\hline \multirow{3}{*}{ DAPSO } & 681 & 10 & \multirow{3}{*}{92.55} & \multirow{3}{*}{56.13} & \multirow{3}{*}{0.9654} & \multirow{3}{*}{0.9829} \\
\hline & 600 & 18 & & & & \\
\hline & 719 & 31 & & & & \\
\hline
\end{tabular}

From Fig. 3, it is clear that DAPSO has better results than ADPSO and the best case is blue curve. It is interesting that DAPSO in Case-II (light green curve4) has better voltage profile than ADPSO in all cases. This fact is more obvious and attractive by considering bus- 18 voltage which is the lowest voltage without DG installation and experience more improvement after installing DG units than the other buses. This phenomenon is due to the fact that DAPSO could escape local minima and seek vast search space dynamically which depends on to its structure.

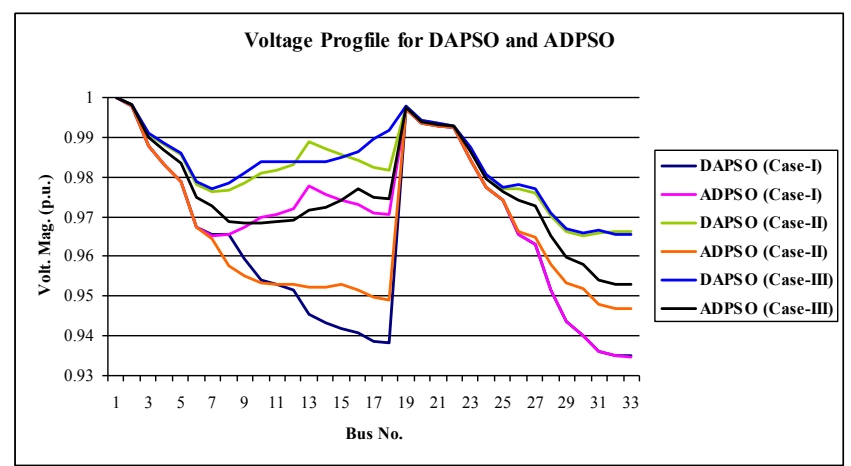

Fig. 3. IEEE 33-bus radial distribution system voltage profile for DAPSO and ADPSO for three Case-I (single-DG), Case-II (double-DG) and CaseIII(triple-DG)

\section{B. PSO Techniques, IEEE 69-bus Radial Distribution System}

The second test system is the IEEE 69-bus radial distribution system with the total load of $3.80 \mathrm{MW}$ and 2.69 MVar. Data for this system are as in [23]. Results are furnished in Table IV which is evaluated for three DG units placement.

TABLE IV. TRIPLE-DG PLACEMENT RESULTS IN IEEE 69-BUS SYSTEM.

\begin{tabular}{|c|c|c|c|c|c|c|}
\hline \multirow{2}{*}{ Technique } & \multicolumn{2}{|c|}{$\begin{array}{c}\text { DG } \\
\text { Installation }\end{array}$} & \multicolumn{2}{|c|}{ Power Loss } & \multicolumn{2}{|c|}{ Bus Voltage } \\
\hline & $\begin{array}{l}\text { Size } \\
(\mathrm{kW})\end{array}$ & $\stackrel{\text { a }}{\text { bus }}$ & $\begin{array}{c}\text { Value } \\
(\mathrm{kW})\end{array}$ & $\begin{array}{c}\text { Decline } \\
(\%)\end{array}$ & $\begin{array}{l}\text { Min. } \\
\text { (p.u.) }\end{array}$ & $\begin{array}{c}\text { Mean } \\
\text { (p.u.) }\end{array}$ \\
\hline Without DG & - & - & 224.89 & - & 0.9092 & 0.9734 \\
\hline \multirow{3}{*}{ AEPSO } & 842 & 6 & \multirow{3}{*}{125.86} & \multirow{3}{*}{44.03} & \multirow{3}{*}{0.9405} & \multirow{3}{*}{0.9812} \\
\hline & 901 & 59 & & & & \\
\hline & 601 & 63 & & & & \\
\hline \multirow{3}{*}{ PSOPC } & 1090 & 37 & \multirow{3}{*}{116.09} & \multirow{3}{*}{48.37} & \multirow{3}{*}{0.9458} & \multirow{3}{*}{0.9833} \\
\hline & 710 & 51 & & & & \\
\hline & 1085 & 58 & & & & \\
\hline \multirow{3}{*}{ EVPSO } & 535 & 47 & \multirow{3}{*}{106.88} & \multirow{3}{*}{52.47} & \multirow{3}{*}{0.9538} & \multirow{3}{*}{0.9833} \\
\hline & 1406 & 59 & & & & \\
\hline & 697 & 65 & & & & \\
\hline \multirow{3}{*}{ ADPSO } & 945 & 2 & \multirow{3}{*}{94.70} & \multirow{3}{*}{57.89} & \multirow{3}{*}{0.9718} & \multirow{3}{*}{0.9914} \\
\hline & 521 & 60 & & & & \\
\hline & 1953 & 62 & & & & \\
\hline \multirow{3}{*}{ DAPSO } & 500 & 9 & \multirow{3}{*}{83.68} & \multirow{3}{*}{62.79} & \multirow{3}{*}{0.9716} & \multirow{3}{*}{0.9895} \\
\hline & 521 & 33 & & & & \\
\hline & 1929 & 62 & & & & \\
\hline
\end{tabular}

Table IV shows the best behavior of DAPSO in results, for the larger radial distribution system, DAPSO has better results. Voltage profile is shown in Fig. 4.

\section{DE Techniques, IEEE 69-bus Radial Distribution System}

Due to the space limitation and huge number of results the IEEE 69-bus test system was used for DE techniques. The optimum results for each DE technique are obtained with population size of 30 , after 30 runs, $C R=0.1$ and for power factor of 0.85 lagging (Table $\mathrm{V}$ ). 


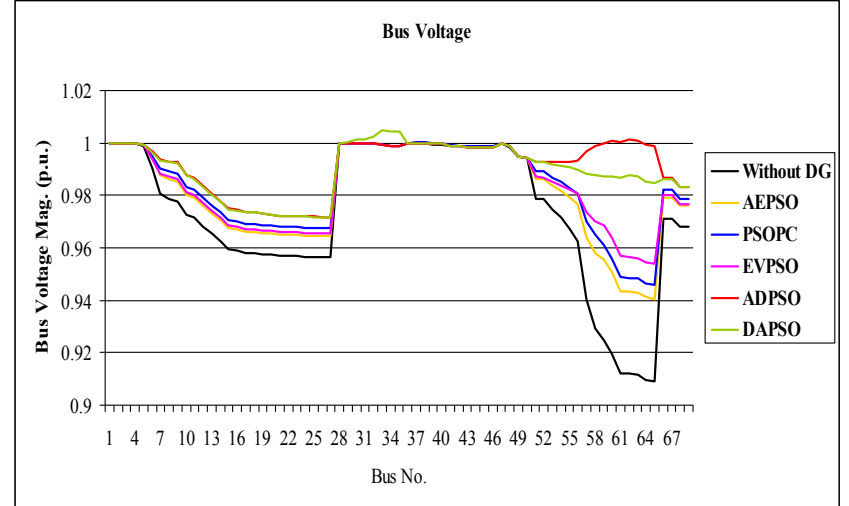

Fig. 4. IEEE 69-bus radial distribution system voltage profile for PSO techniques.

TABLE V. SINGLE DG PLACEMENT RESULTS IN IEEE 69-BUS SYSTEM.

\begin{tabular}{|c|c|c|c|c|c|c|}
\hline \multirow{2}{*}{ Technique } & \multicolumn{2}{|c|}{$\begin{array}{c}\text { DG } \\
\text { Installation }\end{array}$} & \multicolumn{2}{|c|}{ Power Loss } & \multicolumn{2}{|c|}{ Bus Voltage } \\
\hline & $\begin{array}{r}\text { Size } \\
(\mathrm{kW})\end{array}$ & $\underset{\text { bus }}{\stackrel{(a)}{ }}$ & $\begin{array}{c}\text { Value } \\
(\mathrm{kW})\end{array}$ & $\begin{array}{c}\text { Decline } \\
(\%)\end{array}$ & $\begin{array}{l}\text { Min. } \\
\text { (p.u.) }\end{array}$ & $\begin{array}{c}\text { Mean } \\
\text { (p.u.) }\end{array}$ \\
\hline $\begin{array}{l}\text { Without } \\
\text { DG }\end{array}$ & - & - & 224.89 & - & 0.9092 & 0.9734 \\
\hline \multirow{3}{*}{$\begin{array}{c}\text { Self- } \\
\text { Adaptive } \\
\text { DE }\end{array}$} & 603 & 17 & \multirow{3}{*}{117.16} & \multirow{3}{*}{47.90} & \multirow{3}{*}{0.9402} & \multirow{3}{*}{0.9874} \\
\hline & 634 & 52 & & & & \\
\hline & 662 & 60 & & & & \\
\hline \multirow{3}{*}{ BSNN DE } & 556 & 12 & \multirow{3}{*}{127.27} & \multirow{3}{*}{43.41} & \multirow{3}{*}{0.9375} & \multirow{3}{*}{0.9828} \\
\hline & 542 & 33 & & & & \\
\hline & 700 & 60 & & & & \\
\hline \multirow{3}{*}{$\begin{array}{l}\text { Opposition } \\
\text {-based DE }\end{array}$} & 666 & 20 & \multirow{3}{*}{130.62} & \multirow{3}{*}{41.92} & \multirow{3}{*}{0.9374} & \multirow{3}{*}{0.9869} \\
\hline & 577 & 34 & & & & \\
\hline & 677 & 60 & & & & \\
\hline
\end{tabular}

As it can be seen from Table V, the DE techniques can obtain acceptable results compared to PSO techniques. This is because DE techniques have good convergence properties. All of the three DE techniques reduced real power losses more than $40 \%$ with DG sizes less than $2000 \mathrm{~kW}$. While, PSO techniques do this with more DG sizes.

\section{CONCLUSIONS}

In this paper, two types of Swarm-based and Evolutionary Algorithms are used for DG placement problem. Various PSO and DE techniques, as the best and newly proposed Swarm-based and Evolutionary algorithms, were employed for optimal sitting and sizing of the DGs. It was obtained that both PSO and DE techniques have reached acceptable results, and because of good convergence properties, DE techniques could reach the optimum results compared to those of PSOs. However, because of fast convergence capability of PSO techniques, PSO techniques can be used for online applications. For the future works, authors of this paper believe that a combination of PSO and DE techniques for DG placement problem can be effectively used and the obtained results by using the combination of these two types of algorithms may be remarkable.

\section{REFERENCES}

[1] T. Ackermann, G. Andersson, L. Soder, "Distributed generation: a definition." Electric Power System Research, vol. 71, pp. 119-28, 2004. [Online]. Available: http://dx.doi.org/10.1016/j.epsr. 2004.01.006

[2] Qi Kang, Tian Lan, Yong Yan, Lei Wanga, Qidi Wu. "Group search optimizer based optimal location and capacity of distributed generations", Neurocomputing, vol. 78, pp. 55-63, 2012. [Online]. Available: http://dx.doi.org/10.1016/j.neucom.2011.05.030

[3] G. Celli, F. Pilo, "Optimal distributed generation allocation in MV distribution networks", IEEE PES Conf. on Power Industry Computer Applications, PICA 2001, Australia, pp. 81-86.

[4] Keane, M. O'Malley. "Optimal distributed generation plant mix with novel loss adjustment factors", in: IEEE Power Engineering Society General Meeting, 2006.

[5] Y. A. Katsigiannis, P. S. Georgilakis. "Optimal sizing of small isolated hybrid power systems using tabu search", Journal of Optoelectronics and Advanced Materials, vol. 10, no. 5, pp. 1241$1245,2008$.

[6] Duong Quoc Hung, Nadarajah Mithulananthan, R. C. Bansal, "Analytical Expressions for DG Allocation in Primary Distribution Networks", IEEE Trans. on Energy Conversion, vol. 25, 2010.

[7] F. S. Abu-Mouti, M. E. El-Hawary, "Optimal Distributed Generation Allocation and Sizing in Distribution Systems via Artificial Bee Colony Algorithm", IEEE Trans. on Power Delivery, vol. 26, 2011.

[8] T. Niknam, S. I. Taheri, J. Aghaei, S. Tabatabaei, M. Nayeripour, "A modified honey bee mating optimization algorithm for multiobjective placement of renewable energy resources", Applied Energy, vol. 88, pp. 4817-4830, 2011. [Online]. Available: http://dx.doi.org/10.1016/j.apenergy.2011.06.023

[9] G. P. Harrison, A. Piccolo, P. Siano, A. R. Wallace, "Hybrid GA and OPF evaluation of network capacity for distribution generation connections", Electric Power Energy System, vol. 78, pp. 392-398, 2008. [Online]. Available: http://dx.doi.org/10.1016/j.epsr. 2007.03.008

[10] J. Kennedy, R. C. Eberhart, "Particle swarm optimization", in Proc IEEE Int. Conf. Neural Networks, 1995, pp. 1942-1948.

[11] D. Sedighizadeh, E. Masehian, "Particle Swarm Optimization Methods", Taxonomy and Applications, International Journal of Computer Theory and Engineering, vol. 5, pp. 1793-8201, 2009.

[12] R. Storn, K. Price. "Differential evolution-A simple and efficient heuristic for global optimization over continuous space", Journal of Global Optimization, vol. 11, pp. 341-359, 1997. [Online]. Available: http://dx.doi.org/10.1023/A:1008202821328

[13] J. Liu, J. Lampinen, "On setting the control parameter of the differential evolution method", in Proc. 8th Int. Conf. Soft Computing MENDEL 2002, 2002, pp. 11-18. [Online]. Available: http://dx.doi.org/10.1016/j.ijepes.2011.08.023

[14] M. H. Moradi, M. Abedini, "A combination of genetic algorithm and particle swarm optimization for optimal DG location and sizing in distribution systems", Electrical Power and Energy Systems, vol. 34, pp. 66-74, 2012

[15] J. Brest, S. Greiner, B. Boskovic, M. Mernik, V. Zumer, "Selfadapting control parameters in differential evolution: A comparative study on numerical benchmark problems", IEEE Trans. on Evolutionary Computation, vol. 10, no. 6, pp. 646-657, Dec. 2006. [Online]. Available: http://dx.doi.org/10.1109/TEVC.2006.872133

[16] X. Shen, K. Wei, D. Wu, Y. Tong, Y. Li, "A dynamic adaptive dissipative particle swarm optimization with mutation operation", in Proc. IEEE ICCA, 2007, pp. 586-589.

[17] X. Wang, Y. Wang, H. Zeng, H. Zhou, "Particle swarm optimization with escape velocity", Int. Conf. on Computational Intelligent and Security, vol. 1, 2006, pp. 457-460.

[18] S. He, Q. H. Wu, J. Y. Wen, J. R. Saunders, R. C. Paton, "A particle swarm optimizer with passive congregation", Journal of Biosystems, vol. 78, pp. 135-147, 2004. [Online]. Available: http://dx.doi.org/10.1016/j.biosystems.2004.08.003

[19] A. Atyabi, S. Phon-Amnuaisuk, "Particle swarm optimization with area extension (AEPSO)", IEEE/CEC, pp.1970-1976, 2007.

[20] P. Farhadi, H. Shayeghi, T. Sojoudi, M. Karimi, "Customer reliability improvement and power loss reduction in distribution systems using distributed generations", Indian Journal of Science and Technology, vol. 5, pp. 2313-2317, 2012

[21] M. Karimi, P. Farhadi, M. Fard, M. Anwari, "AbSDE Algorithm: A novel approach to solve multistage optimal substation placement", Int. Review of Electrical Engineering (I.R.E.E.), vol. 7, no. 6, pp. 6145-6152, 2012.

[22] S. Rahnamayan, H. R. Tizhoosh, M. M. A. Salama, "Oppositionbased differential evolution", IEEE Trans. on Evolutionary Computation, vol. 12, no. 1, pp. 65-79, Feb. 2008. [Online] Available: http://dx.doi.org/10.1109/TEVC.2007.894200

[23] H. Abdellatif, Z. Khaled, "Efficient load flow method for radial distribution feeders", Journal of Applied Science, vol. 13, p.p. 2741$8,2006$. 